\title{
Rethinking the Collaboration of Civil Engineering and Human Geography
}

\author{
Agus Supriyadi ${ }^{1,2 *}$ \\ ${ }^{1}$ The School of Geography, Nanjing Normal University, Nanjing 210023, China \\ ${ }^{2}$ The Jiangsu Center for Collaborative Innovation in Geographical Information Resource Development and Application, Nanjing 210023, China
}

*Corresponding author: Agus Supriyadi, The School of Geography, Nanjing Normal University, Nanjing 210023, China.

Received Date: April 01, 2020

Published Date: April 24, 2020

\begin{abstract}
In response to the global shift in technology, a heavy burden of responsibility is placed on the sciences to act in the best approach. This study reviews from a different perspective about the collaboration of two fields of science: engineering and human geography. In the management of construction on a large scale, it becomes essential for engineers in development planning and the construction process that consider social and environmental impacts. Thus, the involvement of other fields of knowledge that understand the interaction between humans and the environment becomes a crucial point in efforts to preserve the environment and natural resources. Human geography, which studies human interaction with the environment, will play an essential role in bridging for civil engineers to understand better the social and environmental impacts that arise in a construction project.
\end{abstract}

Keywords: Civil engineering; Human geography; Social and environmental impact; Climate change; Human interaction

\section{Introduction}

In the development of technology, encourages every field of science to innovate in its application in the field. In addition, the global climate change and human population in the world, also affect the way and human behavior with the environment. During the renaissance era, the architect and civil engineering era put forward the beauty, structural ability, and age of buildings as an essential part of planning and development. Preserve engineers did not consider the sustainability of the environment and resources at that time. In the last few decades, since the issue of global warming worldwide, more and more architects and civil engineers have put forward the concept of a building that is very environmentally friendly. However, existing buildings are difficult to adapt to the latest situation facing the world, including the predicted world population that is increasing very significantly. In terms of sustainability, it becomes vital that research in the field of civil engineering also begins to pay attention and also predict humannature interactions in the future. Technology transformation also indirectly brings changes in human behavior in interacting with each other and interacting with nature. Therefore, collaboration in the field of civil engineering with the field of social science, such as human geography, is one of the alternatives to face challenges in the future. The type of building material has accommodated the importance of environmental sustainability; for example, many types of research have begun to consider renewable raw materials such as bamboo and husk ash as a mixture of concrete [1-5]. How about human society changes and culture? Has the civil engineering research done so? A growing opinion is here the importance of understanding human interaction with nature in civil engineering.

\section{Human Geography as Multi-Discipline of Knowledge}

Apart from differences of opinion from the scholars, many scholars agree with the opinion that views human geography as a science that studies the relationship of human interaction with the environment [6,7]. Therefore this field of science has become an important part of conducting collaborative research with the world of civil engineering and construction as well as in urban planning [8]. The rapid development of technology in various fields is inevitable the role of information technology has become an inseparable part, including in the field of geography, how the presence of Geographic 
Information System (GIS) becomes an essential tool in the analysis [9]. For example, how epidemiological data about the occurrence of diseases, the distribution of cases of disease form a pattern, and evidence of contagion can be managed and collect through GIS tools [10-11]. Collaboration between physical geography and the world of Civil Engineering may have become an absolute thing; this looks at how civil engineering students are required to learn about the earth's surface, mapping techniques, and types of soil material. However, the debate that may still arise is how the role of human geography that studies humans interacting on the surface of the earth with the world of civil engineering.

\section{How Civil Engineering Interact with Human Geog- raphy}

In its development, human geography is a social science that collaborates with multiple disciplines, indirectly will also study human behavior and the impact that occurs and whether it has a link between human social interaction with nature $[10,12]$. In the authors' opinion, human geography is a scientific field that reaches a broader perspective and is not only seen as a geography field. In its development, the science of human interaction with nature will involve social, environmental, and economical, then in the field of civil engineering and construction will certainly take into account the interaction between humans as objects of civil engineering product users with their environment. In this case, the role of civil engineering researchers can collaborate by conducting research trying to provide a construction of buildings that facilitate or support the social movement of people with nature or social interaction between humans. Alternatively, further, amid a pandemic situation, COVID-19 becomes interesting if researchers in the field of civil engineering and human geography collaborate to produce the most appropriate building material ideas to participate in reducing the impact arising from this pandemic. For example, research into the use of the most appropriate type of building material in a hospital, explicitly handling pandemic cases, will be important and very valuable in the future.

\section{Rethinking of interface of Civil Engineering and Hu- man Geography}

In the management of construction on a large scale, it becomes important for engineers in development planning, and the construction process is essential to consider social and environmental impacts [13]. In this case, it becomes essential to the field of social science and other fields of science to collaborate with engineers in order to minimize the negative impact. However, the collaboration of various fields of science also requires proper management, because basically, every field of science has its own goals. Thus, in the author's perception, the field of human geography can be an alternative link, which unites the perceptions of various fields of science in a development process. Without prejudice to other fields of science, human geography is a field of science that studies human interaction with the earth and what is on it, and civil engineering is doing a building construction on the surface of the earth that will be used or utilized by humans.

\section{Funding}

This research was supported by the China Scholarship Council (CSC) and the National Natural Science Foundation of China (Grant No: 41471103).

\section{Acknowledgment}

The authors would like to acknowledge the assistance of Professor Tao Wang for giving a broad view and explanation of human geography.

\section{Conflicts of Interest}

The authors declare no conflict of interest.

\section{References}

1. Gautam R Batra, Singh N (2019) A Study on Use of Rice Husk Ash in Concrete. Eng Herit J 3(1): 1-4.

2. Ghavami K (2018) Bamboo as reinforcement in structural concrete elements. Cem Concr Compos 27: 637-647.

3. Lima HC, Willrich FL, Barbosa NP, Ros MA, Cunha BS (2008) Durability analysis of bamboo as concrete reinforcement. Mater Struct 41: 981989.

4. Hossain MA, Rashid MH, Laz OU, Rahman MM (2011) Effect of Rice Husk Ash on Concrete Effect of Rice Husk Ash on Concrete in Proceeding of the Waste Safe 2011-2 ${ }^{\text {nd }}$ International Conference on Solid Waste Management in the Developing Countries, Khulna, Bangladesh.

5. Akeke GA, Ephraim ME, Ukpata JO (2013) Structural properties of rice husk ash concrete. Int J Eng Appl. Sci 3 3, : 57-62,.

6. Flowerdew R (2009) Scientific Method. Int Encycl Hum Geogr pp.43-45.

7. Gibson (2009) Human Geography. Int Encycl Hum Geogr pp.218-231.

8. Dodson J, Gleeson B (2009) Urban Planning and Human Geography. Int Encycl Hum Geogr pp. 77-83.

9. Clarke KC (1986) Advances in Geographic Information Systems. Comput Environ Urban Syst 10(3-4): 175-184.

10. Dorrel, Henderson JP (2018) Introduction to Geography in Introduction to Human Geography, University System of Georgia, pp.2-13.

11. Câmara G, Monteiro AM, Fucks SD, Sá M (2001) Spatial Analysis and GIS : A Primer.

12. Graves S (2017) what is Geography? In Introduction to Human Geography : A Disciplinary Approach (2nd Ed.), California: Department of Geography, California State University, Northridge, pp.1-14.

13. Chowdhury SR (2018) Geo-Environmental Engineering in any Civil Construction. Curr Trends Civ Struct Eng 2:1-2. 